SHORT REPORT

\title{
Development of the Role and Scope of an Academic Mentorship Network for Health Professionals Working with People with Rheumatological and Musculoskeletal Conditions across Europe
}

\author{
Jo Adams ${ }^{1 *}$, Rinie Geenen ${ }^{2}$, Rikke Helene Moe $^{3}$, Yvonne van Eijk-Hustings $^{4}$ \& Christina Opava ${ }^{5}$ \\ ${ }^{1}$ Faculty of Health Sciences Centre of Innovation and Leadership, University of Southampton, Southampton, UK \\ ${ }^{2}$ Department of Clinical and Health Psychology, Utrect University, Utrecht, The Netherlands \\ ${ }^{3}$ National Advisory Unit on Rehabilitation in Rheumatology (NKRR), Dept. of Rheumatology at Diakonhjemmet Hospital, Oslo, Norway \\ ${ }^{4}$ Department of Patient \& Care, Department of Rheumatology, Maastricht, The Netherlands \\ ${ }^{5}$ Department of Neurobiology, Health Care Sciences and Society, Division of Physiotherapy, Karolinska Institutet, Sweden \\ *Correspondence \\ Jo Adams, Professor of Musculoskeletal Health, Arthritis Research UK Centre for Sport, Exercise and Osteoarthritis C floor West block \\ Queen's Medical Centre Derby Road Nottingham NG7 2UH UK. Tel: +44 02380595287. \\ Email: ja@soton.ac.uk
}

Published online in Wiley Online Library (wileyonlinelibrary.com) DOI: 10.1002/msc.1120

\section{Introduction}

Mentorship is designed to help people identify and develop the skills they need to maximize their own potential (Parsloe, 1992). The emphasis of mentoring is on active learning, where the mentee is responsible for identifying their learning needs and is supported in achieving these by a more experienced mentor. This relationship then can serve as an active support mechanism to help mentees make 'significant transitions in knowledge, work or thinking' (Megginson and Clutterbuck, 1995) and 'take charge of their own development, to release their potential and to achieve results which they value' (Connor and Pokora, 2007).

Mentorship programmes can provide a positive approach to support people in their personal and professional development in their work. It is known that mentorship is positively associated with individual, personal benefits such as greater job satisfaction, improved performance and productivity, greater career mobility and opportunity, and career advancement and promotion (Garvey et al., 2009). As such, mentorship is usefully employed across organizations and professions (Parsloe and Leedham, 2009). Mentorship programmes can be found within or outside one's own workplace but may benefit from further development in rheumatology settings. Young rheumatology researchers have already identified that career mentorship (especially in the clinical setting) is a major unmet need of existing mentoring programmes in rheumatology departments in Europe (Frank-Bertoncelj et al., 2014). The development of a mentorship programme across Europe presents a helpful approach to support the development of health professionals (HPs) working in rheumatic and musculoskeletal disease (RMD) settings.

\section{European HPs in Rheumatology}

In 2014, the European HPs in Rheumatology identified academic mentoring as a key development opportunity for the European League Against Rheumatism (EULAR) HP community. The rationale for developing a EULAR academic mentorship programme included:

- To support EULAR HPs to develop academic skills;

- To share the academic expertise across EULAR HP members;

- To continue the development of a EULAR community of HPs;

- To continue the development of mentorship skills in rheumatology care across Europe. 
An academic mentorship working party of HPs from different professional backgrounds and different European countries was convened in December 2014 (JA, RG, RM, YvE). Objectives were defined by the working party included:

- To consider and develop a working definition of the role and scope of a EULAR HP mentor;

- To identify the various possible approaches and components for mentorship to enable a tailored approach for potential mentees

- To provide a guide for the qualities and qualifications of a potential EULAR HP mentor

- To discuss how to establish a potential mechanism for identifying mentees.

\section{Stakeholder involvement and feedback for academic mentorship development}

Early involvement of mentorship stakeholders has been identified as a positive strategy in the development of a mentoring programme (Straus et al., 2008), and, as part of the process of developing a mentoring network for HPs, an initial stakeholder academic mentoring workshop event was held at the 2015 EULAR congress in Rome. The workshop was attended by 43 HPs from 17 countries (Australia, Czech Republic, Estonia, France, Ireland, Italy, Japan, Netherlands, New Zealand, Norway, Slovenia, Spain, Sweden, Switzerland, Turkey, UK and the USA). Following a short presentation on the aims and objectives of mentorship and examples of how mentorship has been previously delivered in other areas, delegates formed small groups to debate and discuss four main topic areas:

1. What role and scope is required from a EULAR HP mentorship programme?

2. What approaches could be considered for mentorship?

3. What qualities and qualifications are required from a potential EULAR HP mentor?

4. How can we identify potential mentees and mentors?

The key discussion points were noted by each group's facilitator and are summarized here, under each topic.

\section{What role and scope is required from a EULAR HP mentorship programme?}

Mentorship was deemed to be timely and an approach that was generally welcomed throughout the EULAR HP membership countries and beyond. EULAR HP workshop attendees confirmed that they wanted a mentorship scheme to help them to gain support from an inspirational healthcare researcher to help them identify the steps they could take in engaging with applied in-country RMD research. There was a general feeling that the mentors chosen as part of the mentorship programme needed to be able to promote ambition and motivate HPs across the EULAR member countries. Mentors could serve as guides, critical friends, a sounding board, confidants, information givers and role models.

\section{a. The role of a EULAR HP mentorship scheme}

The primary role of a EULAR HP mentor was identified as supporting HPs starting out on an academic career to identify and connect with experienced healthcare academics. It was hoped that a EULAR HP mentorship programme would be able to serve as a mechanism for connecting less experienced academic HPs with more senior academic HPs across Europe.

There were various ways of doing this, and suggestions included:

1. Establishing a EULAR HP mentorship website that showed individual healthcare academic mentor profiles. This would be required to be an open and accessible website so that people could see the range of people who had offered to become mentors and see which person they felt was the most appropriate mentor for them.

2. Publishing a database of potential mentors willing to offer support and help on defined topic areas to potentially interested mentees. Mentees would then have a choice over who they felt could best support their needs.

3. Setting up a formal buddy system for new attendees at EULAR, so that a less experienced HP could meet up with, and be supported through the conference by, a more experienced HP. 
4. Having pre-EULAR congress, breakfast or lunchtime mentorship sessions and roundtable subject discussions at each EULAR congress.

\section{b. The scope and reach of a EULAR HP mentorship programme}

Delegates identified that there were some clear priorities for academic mentoring. These included support on:

1. How to read a scientific paper and how to apply the evidence to clinical work

2. How to carry out a literature search

3. Writing a conference abstract, research paper

4. How to present data for conference posters and presentations

5. Defining a research question

6. Specific research methodology and HP outcome measurement

7. Designing a research project

8. Signposting mentees to clinical academic experts and teams (networking opportunities)

9. How to identify funding opportunities and complete research grant application forms.

In order to achieve the above, a website would be required to host online materials that are freely accessible to all mentees. These were requested also to be available in different languages and to be culturally appropriate. It was also hoped that mentors would be proficient in English but be able to provide mentorship in languages other than English too.

\section{Which approaches could be considered for HP mentorship?}

The EULAR HP mentorship programme could be delivered via a variety of approaches:

- The annual EULAR congress would provide an opportunity to hold key meetings and workshops, and a chance for people to be buddied by mentors using either 1:1 or group mentorship meetings.

- Interim measures between EULAR congresses would include Skype and telephone contact, and support via group webinar opportunities.

- An internship model, supported by a EULAR bursary or Pharma (educational grant) sponsorship, may also be appropriate for EULAR, with mentees visiting mentors in their country of residence on short internship projects.

It was also hoped that established HP research teams which have EULAR mentors within them could be open to new members to join, to act as co-authors or co-applicants.

\section{The qualities and qualifications required from a potential EULAR HP mentor}

The attendees mentioned mentorship qualities that largely overlapped with findings from a previous qualitative study (Cho et al., 2011). Delegates acknowledged that it would be difficult to find an individual who possessed all the attributes considered necessary to be a good mentor, but several qualities were considered desirable.

It was assumed that mentors would be able to assist with academic career guidance for individuals. Moreover, they would know how to network and help to support mentees to maximize wider networks. They would also be able to signpost people and help them to navigate a research process. They would be experienced and have already demonstrated that they were accomplished (i.e. have a track record) in HP research. They would be expected to have national and, in some instances, international standing. Good communication skills, with a combination of academic and clinical experience, were considered essential. Most importantly, they would need sound academic skills in research methods appropriate to each mentee.

Delegates identified key areas for developing a clear mentorship agreement; these have previously been identified and reported by Detsky et al.., (2007). It was felt that mentors would need to be clear about the type of mentorship relationship that they would be happy to consider - for example, if the contact would be a one off or longer term mentorship relationship.

Most importantly it was felt mentors should be able to commit to the time required and agree to support mentees. It was considered important that mentors would be able to provide timely responses to request for support. It was not considered essential that mentors should always be from the same professional background or same country although in some instances this may be beneficial. Some suggested that having multiple mentors from different countries could be helpful.

Delegates identified key personal qualities that were considered equally important for mentors as prior 
experience. These included mentors being accessible, approachable, professional, patient, persistent, passionate and altruistic. It was hoped that mentors would have a keen sense of supporting junior HP researchers to develop and grow. They were also expected to be kind. It was hoped that a EULAR HP academic mentor would be able to inspire others to engage in HP research.

\section{Identification of potential mentees and mentors}

In some countries, it was identified that such mentorship schemes should be highlighted at undergraduate or pre-registration level, to motivate students to engage with RMD research communities from an early point in their career. This would also bring attention to the support and enthusiasm available within European RMD research. Various options for identifying mentees were identified; these included:

- National communities/HP societies/EULAR study groups

- Professional registries associations

- Key HP leaders who may already have team members and clinical contacts engaged with in their research programmes

- EULAR annual congress attendees.

To identify mentors, it was suggested that professional registers within countries might be a useful target, and that employing EULAR country presidents to snowball mentorship requests could be a positive strategy. Profession-specific directors would also be valuable allies in recruiting possible mentors.

\section{Further observations}

Within groups, there were clear differences in the level of mentorship that people wanted and the expectations of what an academic mentor could offer on a voluntary basis. This differed between individuals from different countries and different professional backgrounds.

It is evident that professional and research development across EULAR member countries varies considerably. In the UK, for instance, clinicians and academics are already part of a professional culture that is well supported by national mentorship opportunities - for example, through separate professional bodies, British Health Professionals in Rheumatology and the Council for Allied Health Professional Research.
Finally, a clear message that emerged was that mentees wanted a mentor who was fluent in English, to help to support them through the publication process for international conferences and journals, but also able to mentor them in their own language.

\section{Summary}

The workshop provided an open forum to debate and discuss the aspirations for a mentorship scheme within EULAR HPs, and the possible scope and remit. Some practical examples on how this could be realized were presented and offer routes to the next stages of developing a EULAR HP mentorship network. What is evident is that expectations of academic mentorship relating to time, scope and support available need to be defined clearly at the outset. Potential mentees need to drive the mentorship relationship, with the responsibility for active learning remaining with the mentee. However, for any mentorship programme to work and have the input of mentors, clear definitions about what mentors can provide must also be clearly articulated and agreed, to ensure that expectations are realistic and sustainable.

\section{Conclusion}

Academic mentorship for EULAR HPs working in RMD settings has been identified as an area for development across Europe. Sharing and supporting academic expertise and good practice between professions and between countries has been agreed as a positive step to helping support the academic development of all HP groups across Europe who are working with people with RMD conditions.

\section{Acknowledgements}

The authors would like to thank Fiona Cramp, University of West England, for contributing material and Professor Tony Redmond and Dr Yeliz Prior for group facilitation during the EULAR 2015 mentorship workshop.

\section{REFERENCES}

Cho CS, Ramanan RA, Feldman MD (2011). Defining the ideal qualities of mentorship: A qualitative analysis of the characteristics of outstanding mentors. American Journal of Medicine 124: 453-8. 
Connor MP, Pokora JB (2007). Coaching and Mentoring at Work: Developing Effective Practice. Maidenhead: Open University Press (McGraw Hill Education).

Detsky AS, Baerlocher MO, Detsky MD (2007). Academic mentoring - How to give it and how to get it. JAMA 297: 2134-6.

Frank-Bertoncelj M, Hatemi G, Ospelt C, Ramiro S, Machado P, Mandl P, Gossec L, Buch MH (2014). Mentoring of young professionals in the field of rheumatology in Europe: Results from an EMerging EUlar NETwork (EMEUNET) survey. Clinical and Experimental Rheumatology 32: 935-41.

Garvey R, Stokes P, Megginson D (2009). Coaching and Mentoring: Theory and Practice. London: Sage.
Megginson D, Clutterbuck D (1995). Mentoring in Action. London: Kogan Page.

Parsloe E (1992). Coaching, Mentoring and Assessing - A Practical Guide to Developing Competence. London: Kogan Page.

Parsloe E, Leedham M (2009). Coaching and Mentoring: Practical Conversations to Improve Learning. London: Kogan Page.

Straus SE, Graham ID, Taylor M, Lockyer J (2008). Development of a mentorship strategy: A knowledge translation case study. Journal of Continuing Education in the Health Professions 28: 117-22. 